\title{
Statistical analysis of the ion density measured by the satellite DEMETER in relation with the seismic activity*
}

\author{
Michel Parrot" \\ Laboratoire de Physique et Chimie de l'Environnement et de l'Espace, Université d'Orléans, \\ CNRS, 3 A Avenue de la Recherche Scientifique, 45071 Orléans cedex 2, France
}

\begin{abstract}
This paper is related to study of the ion density recorded by the low altitude satellite DEMETER. It will present ionospheric perturbations observed during large seismic events. As the ionosphere is highly variable, the paper will show a statistical analysis performed on the plasma parameters during night time. An algorithm has been implemented to detect crests and troughs in the data before world-wide earthquakes. The earthquakes have been classified depending on their magnitude, depth, and location (land, below the sea, close to a coast). Due to the orbit, DEMETER returns above the same area every day (once during day time, once during night time) but not at the same distance of a given epicenter. Then, for each earthquake, data have been checked until 15 days before the shock when the distance between the trace of the orbit and the epicenter is less than $1500 \mathrm{~km}$. The results of the statistical analysis are presented as functions of various parameters. A comparison is done with two other databases where, on one hand, the location of the epicenters has been randomly modified, and on the other hand, the longitude of the epicenters has been shifted. Results show that the number and the intensity of the ionospheric perturbations are larger prior to earthquakes than prior to random events, and that the perturbations increase with the magnitude.
\end{abstract}

Key words: ionosphere; earthquake; satellite; statistic

CLC number: P352.4 Document code: A

\section{Introduction}

During more than 30 years, attempts have been made to attribute some ionospheric perturbations to the preparation of earthquakes, and then to claim that this could be a very efficient short-term precursor. A lot of works also deal with the possible mechanisms to explain these perturbations in the ionosphere. Many hypotheses and modelling have already been published and they can be found for example in monographs published by Hayakawa and Fujinawa (1994), Hayakawa (1999), Hayakawa and Molchanov (2002), Hayakawa (2009), in books by Gokhberg et al. (1995), Pulinets and Boyarchuk (2004), Molchanov and Hayakawa (2008), in special issues of different journals (Parrot and Johnston,

\footnotetext{
* Received 21 February 2011; accepted in revised form 13 August 2011; published 10 December 2011.

† Corresponding author. e-mail: mparrot@cnrs-orleans.fr

(c) The Seismological Society of China and Springer-Verlag Berlin Heidelberg 2011
}

1989, 1993; Hayakawa, 1996, 2002; Hayakawa et al., 2004), in reviews by Molchanov (1993), Hayakawa (1997), Tronin (2006), Pulinets (2007, 2009), Freund (2009), Harrison et al. (2010), and references therein. In the past, many ionospheric perturbations have been detected in relation with seismic activity either from ground or onboard satellites, and see for example, Hayakawa et al. (2000), Liu et al. (2006). DEMETER was the first satellite with a complete payload specially dedicated to this scientific objective (Parrot, 2006). With its data, many ionospheric perturbations have been observed in relation with earthquakes and examples can be found in Parrot et al. (2006), Sarkar et al. (2007), Ouyang et al. (2008), Zhu et al. (2008), Zeng et al. (2009), Zhang et al. (2009a, b, c, 2010a, b, 2011), Akhoondzadeh et al. (2010), Bankov et al. (2010), He et al. (2010), Zlotnicki et al. (2010). But the point is that these ionospheric perturbations can be triggered by other natural phenomena, the main one being the 
solar activity. It is necessary to search for a possible relation between the ionosphere and the seismic activity using a statistical analysis with a lot of events. This is possible with the DEMETER data because the lifetime of the mission was more than six years.

A statistical analysis with the electric field data recorded by DEMETER has already been undertaken (Nemec et al., 2008, 2009). In this paper a different statistical analysis with the ion density will be shown. The DEMETER payload is briefly described in section 2. In section 3 , individual events which occurred before the main shocks are shown. The results of the statistical analysis are presented in section 4 . Discussion and conclusions are provided in section 5 .

\section{The DEMETER satellite}

DEMETER is a low-altitude satellite $(710 \mathrm{~km})$ launched in June 2004 onto a polar and circular orbit which measures electromagnetic waves and plasma parameters all around the globe except in the auroral zones (Parrot, 2006). The altitude of the satellite was decreased to $660 \mathrm{~km}$ in December 2005. The satellite's science mission has come to an end in December 2010. Due to technical reasons, data are only recorded at invariant latitudes less than $65^{\circ}$. The orbit of DEMETER is nearly sun-synchronous and the up-going half-orbits correspond to night time (22:30 LT) whereas the downgoing half-orbits correspond to day time (10:30 LT). Nearly sun-synchronous means that, everyday, the satellite does not return exactly above the same point but above the same area (it could be at more than $1000 \mathrm{~km}$ from the point flew over the days before). To study the variations of the ion density, the payload of DEMETER includes an instrument named IAP (Instrument Analyseur de Plasma) which gives ion density with a 4-sec time resolution. Details of the IAP experiment can be found in Berthelier et al. (2006).

\section{Examples of ionospheric pertur- bations}

The first example shows plasma density variations observed by the DEMETER spacecraft in the vicinity of a very powerful earthquake in Chile. This earthquake of moment magnitude 8.8 occurred on February 27, 2010 at $06: 34: 14 \mathrm{UT}$ with an epicenter located at $35.85^{\circ} \mathrm{S}$, $72.72^{\circ} \mathrm{W}$. The ion and electron densities shown in Figure 1 have been recorded by the satellite along an orbit close to the epicenter on February 26, 2010, i.e., one day before the earthquake. From the top to the bottom, the panels show the electron density and the electron temperature measured with Instrument Sonde de Langmuir (ISL) (Lebreton et al., 2006), the $\mathrm{O}^{+}$ion density and the ion temperature both from IAP. The bottom panel indicates the satellite closest approach of past and future earthquakes epicenters that are within $2000 \mathrm{~km}$ from the DEMETER orbit. The $y$-axis represents the distances $D$ between the epicenters and the satellite, from $750 \mathrm{~km}$ up to $2000 \mathrm{~km}$. The symbols are filled green squares for post-seismic events, filled red triangle for pre-seismic events. The colour scale on the right represents the time interval between the earthquakes and the DEMETER orbit with a colour gradation from $>30$ days up to a $0-6 \mathrm{~h}$ interval. The empty symbols have similar significations except that they are related to the conjugate points of the epicenters (the distance $D$ is then the distance between the conjugate points of the epicenters and the satellite). The symbol sizes correspond to earthquakes of magnitude 5-6,6-7, and $>7$. The numerous red triangles are related to the main shock and to the aftershocks. Their elongated positions indicate that the DEMETER orbit is almost parallel to the rupture fault. It is shown that the electron density and the $\mathrm{O}^{+}$density have the same variation. These densities present a clear fluctuation when the satellite arrives above the future epicenter. Other ionospheric perturbations concerning this earthquake have been published by Píša et al. (2011). Checking the three preceding years they have also shown that these perturbations are very uncommon in this area.

A second example of ionospheric variations is shown in Figure 2. It concerns two shallow earthquakes (depth=10 km) which occurred close to this DEMETER orbit of November 23, 2009. The red triangle at 09:32:27 UT corresponds to an earthquake of magnitude 6.1 which would occur on November 28, 2009 at 09:21:15 UT, whereas the red triangle at 09:34:33 UT corresponds to an earthquake of magnitude 6.8 which would occur on November 24, 2009 at 12:47:15 UT. The locations of these two earthquakes are $\left(29.28^{\circ} \mathrm{S}\right.$, $\left.182.98^{\circ} \mathrm{E}\right)$ in the Kermadec Islands area and $\left(20.64^{\circ} \mathrm{S}\right.$, $\left.185.93^{\circ} \mathrm{E}\right)$ in the Tonga Islands area, respectively. Each time when the satellite is close to the epicenters a variation of the electron density (top panel) and the ion $\mathrm{O}^{+}$ density (middle panel) is observed.

A last example is shown in Figure 3. From the top to the bottom, the panels show the electron density, the ion density, and the positions of the epicenters along the 

DEMETER
Date: $2010-02-26$
Orbit: $30256 \_1$
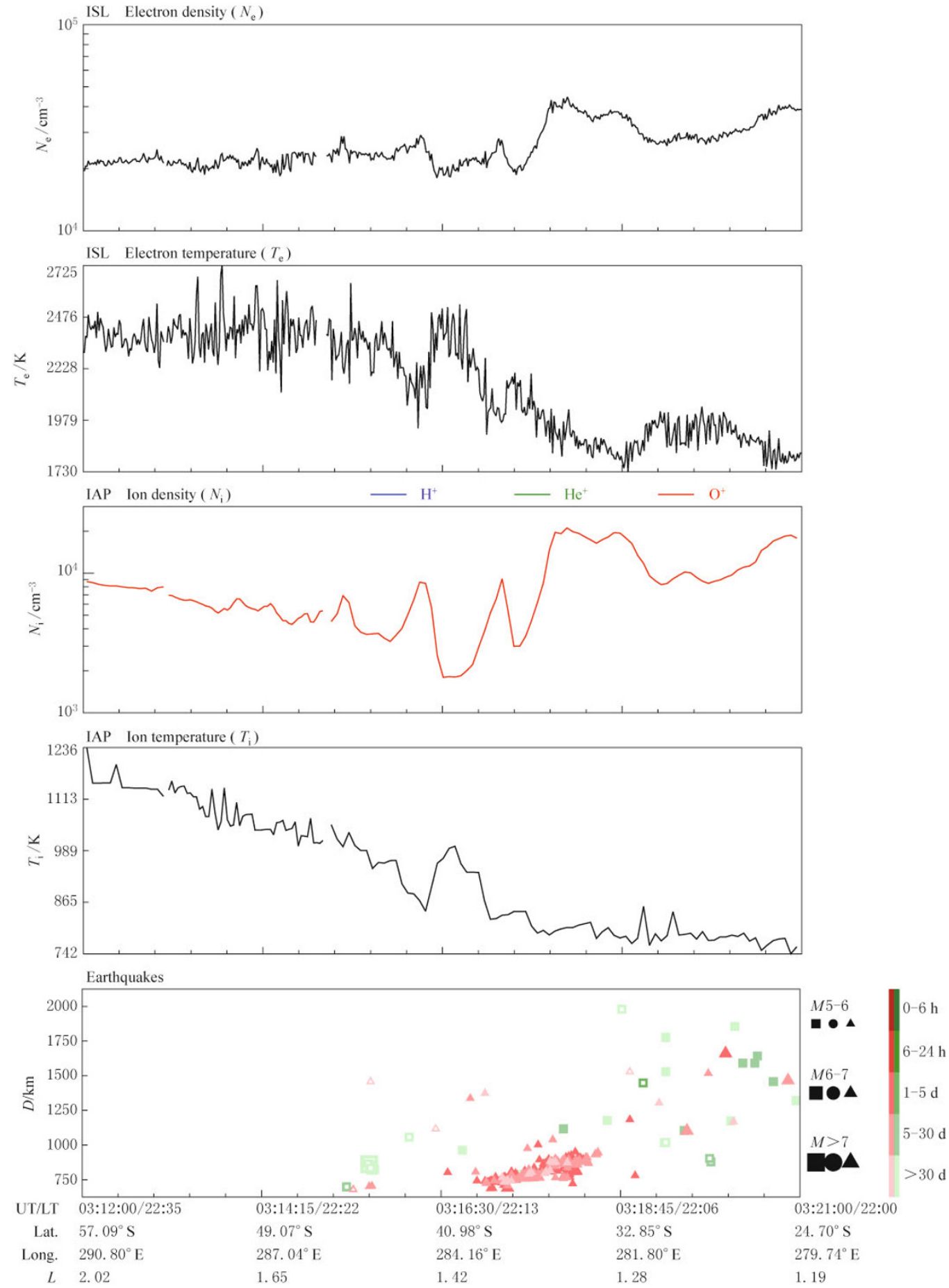

Figure 1 Data recorded on 26 February, 2010 between 03:12:00 UT and 03:21:00 UT. From the top to the bottom the plots represent the electron density, the electron temperature, the ion density, the ion temperature, the distance and magnitude of coming earthquakes as function of the time. The density of the $\mathrm{O}^{+}$ion is only shown because the two other densities $\left(\mathrm{H}^{+}\right.$and $\left.\mathrm{He}^{+}\right)$are out of the scale. In the bottom panel, the red triangles are related to the future main shocks and aftershocks, whereas the green symbols are related to past earthquakes. Fluctuations of the density are observed between 03:15:10 UT and 03:19:00 UT. The parameters below the plots indicate that the observation took place during night time along the rupture zone of the earthquakes in Chile. 


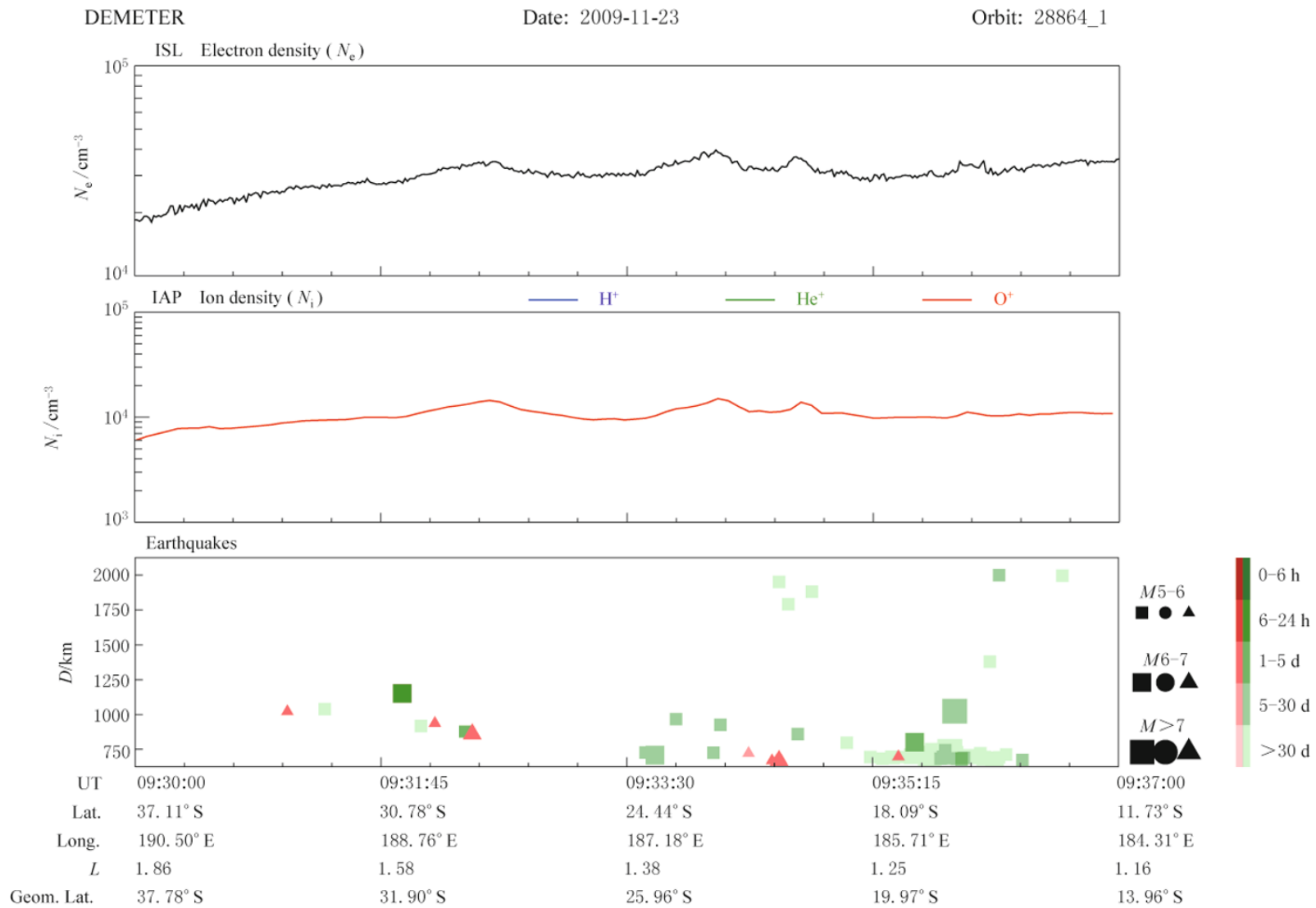

Figure 2 Data recorded on 23 November, 2009 between 09:30:00 UT and 09:37:00 UT. From the top to the bottom the plots represent the electron density, the ion density, the distance and magnitude of coming earthquakes as function of the time (same symbols as in the bottom panel of Figure 1). Perturbations of the density are observed at 09:32:20 UT and around 09:34:30 UT. The parameters below the plots indicate that the observation took place during night time in the Pacific Ocean.

orbit. It can be seen that both ion and electron densities have a perturbation at the location of the closest approach to the epicenter (red triangle in the bottom panel).

\section{The statistical analysis}

It must be mentioned that variations of ionospheric parameters are not only due to earthquakes. There are numerous possibilities of ionospheric perturbations which could come from other sources such as solar activity, acoustic gravity waves (AGW), travelling ionospheric disturbances, plasma dynamics, large meteorological phenomena. There are also many earthquakes, and people thinking that seismic activity cannot influence the ionosphere could say that it is not very difficult to associate an ionospheric variation with the occurrence of an earthquake a few hours or a few days after. In the examples which have been given in the past a great care has been taken to show that these ionospheric variations associated with seismic activity are uncommon at the location and at the time when they are observed.

On the other hand, with satellite data we do not find ionospheric perturbations for all earthquakes. It could perhaps be due to the crust composition and soil configuration. But also we do not expect to have continuous ionospheric perturbations and with a single satellite we are 'above' a given future epicenter only during three minutes per day (night time half-orbit). Here the term 'above' means at a distance less than $1500 \mathrm{~km}$.

For these two above-mentioned reasons we prefer to search for a possible influence of the seismic activity on the ionosphere with a statistical analysis. An automatic software to detect density fluctuations has been developed. The inputs are the earthquake list and the DEMETER data. The earthquakes have been selected with a magnitude larger than or equal to 4.8 and we have associated for each of them a parameter related 


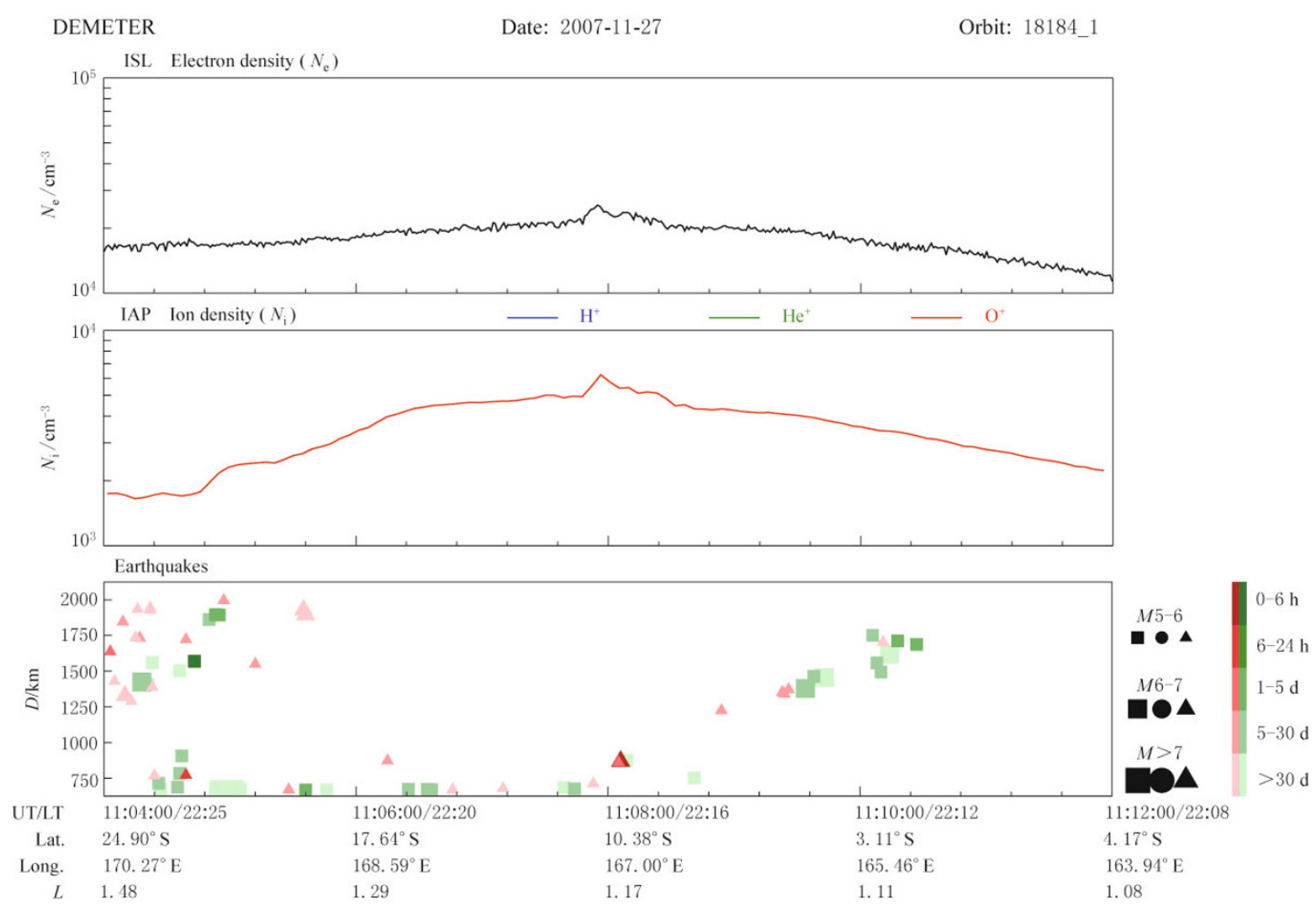

Figure 3 Example of density perturbation observed at 11:08 UT on November 27, 2007 when the satellite is close to the epicenter of an earthquake of magnitude 6.6 which occurs 42 minutes after.

to the position of the epicenters: below the sea, close to a coast, or inland. It is known that the number of earthquakes decreases when their magnitudes increase, and the choice of a low bound of 4.8 for the magnitude of earthquakes is the result of a compromise: it is an accepted fact that an earthquake with large magnitude will produce a larger ionospheric perturbation if any, but our statistical analysis needs enough events close to the satellite orbit to be significant. During the considered period (August 2004 to October 2009) there are 17366 earthquakes with magnitude larger than or equal to 4.8. The software searches for the data of the orbits which are close to the epicenters (less than $1500 \mathrm{~km}$ ) between 0 and 15 days before each earthquake. It only keeps one night time half-orbit per day. If there are two orbits, it keeps the closest one. It is possible that for a given earthquake there is no half-orbit for a given day because the data have not been recorded or because the half-orbit is too far. To detect a variation the software considers the DEMETER ion density data during three minutes around the closest approach to the future epicenter of the earthquake. The data are smoothed and a variation is evaluated by comparison with the back- ground level along this part of the orbit. It is done using the change of the derivative sign.

At the end the software produces a final database with the results. For each earthquake, the first line of the database gives information about it (date, time, latitude, longitude, magnitude, depth, and position). The following 15 lines give information on the data recorded along the half-orbits. The second line is related to the 24 hours before the earthquake, then the third line to the period $(-48 \mathrm{~h},-24 \mathrm{~h})$, and so on. The informations are the half-orbit number, the date and the time when the half-orbit is closest to the epicenter, the date, the time, and the position when the automatic software detects a variation in the ion density, and a parameter $A$ which gives the percentage of this variation relative to the background. It could occur that the software detects no variation.

In order to evaluate the results of the automatic detection software working with the earthquake list, we have considered two other lists with random data. First we have taken the list of earthquakes but we have randomly changed their latitudes and longitudes (keeping the same time). The resulting database after the 
software application is called RAND1. Second we have taken the same list of earthquakes but we have only shifted their longitudes $25^{\circ}$ to the west (keeping the same latitude and the same time). After the software application this third database is called RAND2. Why do we perform this shift of the longitude? When you plot a histogram of the earthquake latitudes (see Figure 4) one can see that most of the earthquakes are concentrated around the equator. On the other hand, it is known that, during night time, natural occurrence of ionospheric perturbations is also more concentrated around the equator (see for example, $\mathrm{Su}$ et al., 1998; Su

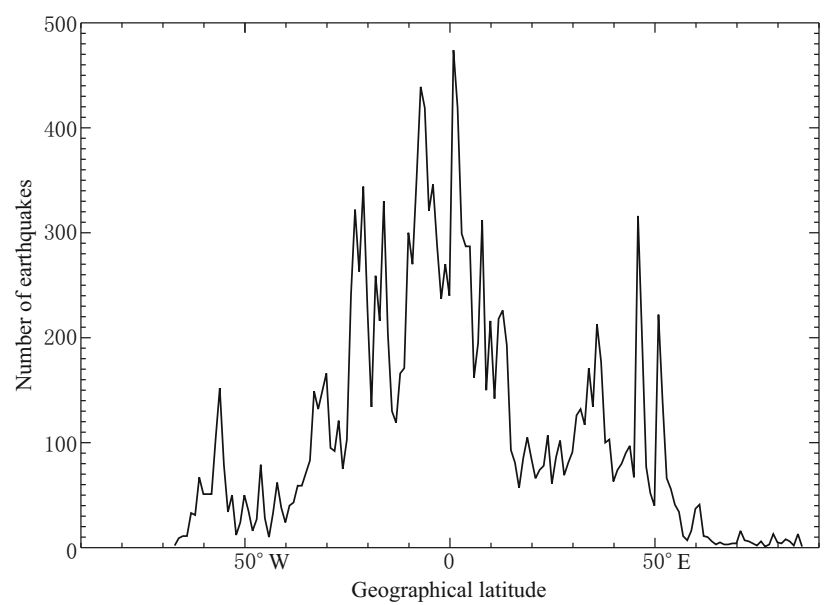

Figure 4 Histogram showing the number of the earthquakes as a function of their geographical latitude.

et al., 2006; Burke et al., 2009; Kelley, 2009). Here, "natural" means not related to the seismic activity. Then with RAND2 we have a database which fits more with the reality for our comparison because we have kept the latitudinal positions of the earthquakes. It must also be noticed that events in RAND2 are not above seismic areas (oppositely to RAND1 where it is possible that some events could be above seismic areas).

In order to reduce the effect of the solar activity we have eliminated the data when the $3 \mathrm{~h} K_{\mathrm{p}}$ index is larger than 3.3. We have also not taken into account the aftershock data when the time of the aftershock is too close to the time of the main shock in order not to mix pre and post seismic effects. It is known that at the exact time of the earthquakes you have a propagation of an AGW which can perturb the ionosphere. For example in Figure 2, one can observe at 09:35:57 UT a variation of the densities when the satellite is above epicenters of past earthquakes (green symbols). Then, $N$ is the number of days between the main shock and the aftershock, and if $N$ is less than 15 , then we have only considered aftershock data for the $N-1$ days before this aftershock.

This automatic software to detect variations is certainly not perfect because the shapes of the ionospheric perturbations could be very different. We have examples with very sharp peaks or very smooth peaks of the ion density. But we have run in the same way the software on the three lists to search for ionospheric perturbations and to produce three databases (earthquakes, RAND1, and RAND2). Then the databases have been used and the results are shown in Table 1. The table numbers represent the ratio between the total number of perturbations when the parameter $A$ is above a given threshold and the total number of cases. Checking the first line it can be seen that, as it was expected, there are perturbations when events with random positions are selected (RAND1) and there are more perturbations when these random events are close to the equator (RAND2). This corresponds to the natural fluctuations in the ionosphere. When we consider the earthquake database, the number of perturbations is larger than the one with RAND2. The other interesting point is that more intense are the earthquakes, more important is the number of perturbations. The second and the third lines are related to earthquakes with epicenters below the sea and inland, respectively. Two remarks can be made. On one hand, the number of perturbations for inland earthquakes is not very important and one needs magnitudes larger than 6 to obtain a number of perturbations larger than the background (RAND2). Oppositely, the number of perturbations for earthquakes with epicenters below the sea is much larger than the background.

Table 1 The statistic results concerning the number of perturbations

\begin{tabular}{ccccccc}
\hline & RAND1 & RAND2 & $M>4.8$ & $M>5.0$ & $M>5.5$ & $M>6.0$ \\
\hline \multirow{2}{*}{ All } & 21.3 & 23.8 & 24.2 & 24.7 & 25.2 & 25.7 \\
& $(15498)$ & $(5954)$ & $(6026)$ & $(3502)$ & $(943)$ & $(279)$ \\
Sea & 23.9 & 25.4 & 30.5 & 30.4 & 30.9 & 31.4 \\
& $(4114)$ & $(2666)$ & $(1797)$ & $(1097)$ & $(301)$ & $(76)$ \\
Inland & 18.7 & 21.5 & 20.0 & 20.5 & 21.6 & 22.7 \\
& $(4956)$ & $(2551)$ & $(2001)$ & $(1157)$ & $(314)$ & $(98)$ \\
\hline
\end{tabular}

Note: The two first columns are related to the random databases RAND1 and RAND2. The other columns concern the earthquake database when we select the earthquake magnitude. From the top to the bottom, the lines are related to all earthquakes, earthquakes with epicenters below the sea, and inland epicenters. The numbers in parenthesis are the numbers of events. 
This behaviour is confirmed in Tables 2 and 3 . In Table 2, we consider $\bar{A}$ the average value of $\mathrm{A}$ for each earthquake (event) when this parameter exists and whatever is its value, and we average $\bar{A}$ for all earthquakes (events). In Table 3 , we consider $A_{\max }$ the maximum value of $A$ for each earthquake (event) when this parameter exists and we average $A_{\max }$ for all earthquakes (events). One can see that the average intensity of the perturbations and the maximum intensity of these perturbations have similar features: (1) they are more intense for the earthquake database than for RAND2, (2) they increase with the magnitude, and (3) the intensity is larger when epicenters are below the sea.

Table 2 The statistic results concerning the average intensity of the perturbations

\begin{tabular}{cccccc}
\hline & RAND2 & $M>4.8$ & $M>5.5$ & $M>6.0$ & $M>6.5$ \\
\hline \multirow{2}{*}{ All } & 5.67 & 5.90 & 5.95 & 6.45 & 6.53 \\
& $(11009)$ & $(11217)$ & $(1780)$ & $(550)$ & $(144)$ \\
Sea & 5.86 & 5.77 & 5.76 & 6.71 & 7.30 \\
& $(5026)$ & $(3214)$ & $(523)$ & $(140)$ & $(32)$ \\
Inland & 5.49 & 5.61 & 5.71 & 5.97 & 6.77 \\
& $(4552)$ & $(3336)$ & $(517)$ & $(169)$ & $(44)$ \\
\hline
\end{tabular}

Note: The first column is related to the random database RAND2. The other columns concern the earthquake database when we select the earthquake magnitude. From the top to the bottom, the lines are related to all earthquakes, earthquakes with epicenters below the sea, and inland epicenters. The numbers in parenthesis are the numbers of events.

Table 3 The statistic results concerning the maximum intensity of the perturbations

\begin{tabular}{cccccc}
\hline & RAND2 & $M>4.8$ & $M>5.5$ & $M>6.0$ & $M>6.5$ \\
\hline \multirow{2}{*}{ All } & 8.74 & 9.28 & 9.40 & 9.98 & 10.3 \\
& $(11009)$ & $(11217)$ & $(1780)$ & $(550)$ & $(144)$ \\
Sea & 9.18 & 9.53 & 9.44 & 11.0 & 12.5 \\
& $(5066)$ & $(3214)$ & $(523)$ & $(140)$ & $(32)$ \\
Inland & 8.21 & 8.61 & 9.02 & 9.22 & 9.64 \\
& $(4552)$ & $(3336)$ & $(517)$ & $(169)$ & $(44)$ \\
\hline
\end{tabular}

Note: The first column is related to the random database RAND2. The other columns concern the earthquake database when we select the earthquake magnitude. From the top to the bottom, the lines are related to all earthquakes, earthquakes with epicenters below the sea, and inland epicenters. The numbers in parenthesis are the numbers of events.

Considering that the Chile is an important seismic zone and that we have already observed in this area numerous ionospheric perturbations in relation with earthquakes, the software was implemented on this restricted zone (geographical latitude between $50^{\circ} \mathrm{S}$ and $10^{\circ} \mathrm{S}$, geographical longitude between $275^{\circ}$ and $295^{\circ}$ ). The results are in Table 4 . Due to the shift of the earth- quake longitudes to the west there is no inland event in the RAND2 database. For earthquakes larger than 6 and with epicenters below the sea, the result was not displayed because the number of earthquakes (indicated in parenthesis) is far too low. Table 4 displays the results concerning the average intensity and it can be compared with Table 2. It is seen that the ionospheric perturbations before earthquakes are much more important above Chile than in the rest of the world.

Table 4 The statistic results for the Chile area concerning the average intensity of the perturbations

\begin{tabular}{cccc}
\hline & RAND2 & $M>4.8$ & $M>6.0$ \\
\hline \multirow{2}{*}{ All } & 6.59 & 7.75 & 8.45 \\
& $(564)$ & $(483)$ & $(29)$ \\
Sea & 6.59 & 7.64 & \\
& $(564)$ & $(19)$ & \\
Inland & NaN & 7.64 & 8.03 \\
& $(0)$ & $(357)$ & $(25)$ \\
\hline
\end{tabular}

Note: The first column is related to the random database RAND2. The two other columns concern the earthquake database when we select the earthquake magnitude. From the top to the bottom, the lines are related to all earthquakes, earthquakes with epicenters below the sea, and inland epicenters. The numbers in parenthesis are the numbers of events.

\section{Discussion and conclusions}

In the past literature, many examples of ionospheric perturbations prior to seismic activity have been shown and, in addition, few events have been presented in this paper. These perturbations occur in the close vicinity of earthquake epicenters a few hours or a few days before the shock. But many other phenomena can perturb the ionosphere and, as people may have one's doubts about the relation between the ionosphere and the Earth's crust despite of the various mechanisms briefly mentioned in the introduction, a statistical analysis has been performed with a huge number of events.

It shows that there are more ionospheric perturbations close to the epicenters of future earthquakes than prior to events at random positions. It also indicates that the number and the intensity of the perturbations are more important when the magnitude of the earthquakes increases.

One surprising result is that there are more perturbations for earthquakes with an epicenter below the sea. This could be linked to a possible mechanism of generation of these ionospheric perturbations. For instance, it is known that the electrical conductivity is larger above the sea. It is premature to attribute these perturbations to a specific mechanism but it is known that, for 
example, radon emanation (Pulinets, 2007, 2009; Harrison et al., 2010) can change the atmospheric electrical conductivity. It has also been shown that the Earth's crust of the Chile induces more perturbations prior to earthquakes than in another seismic part of the world.

In the future, the earthquake database will be further exploited. It is intended to study more carefully the earthquakes which produce perturbations in order to try to extract some common characteristics. At the end, the last job will be to automatically:

- search for ionospheric perturbations in the complete satellite data set of ionospheric densities,

- eliminate perturbations due to known ionospheric phenomena (for example, solar activity),

- eliminate perturbations not above a seismic zone, and,

- check if each selected perturbation corresponds to a future earthquake.

This attempt to predict earthquakes will of course generate false alarms and wrong detections, but it is expected that the number of true detections will be larger, at least for powerful earthquakes. Nevertheless it will remain difficult to predict the exact position, time and magnitude of the earthquakes. Concerning the position, it will be useful to consider the fault system which is already known at the Earth's surface. This will improve the accuracy on the epicenter location. Concerning the time and the magnitude, it will be difficult, facing to an unusual ionospheric perturbation, to say if it is due to a large earthquake occurring in a few days or to a small earthquake occurring in a few hours.

Acknowledgements This work was supported by the Centre National d'Etudes Spatiales. It is based on observations with the plasma analyser IAP embarked on DEMETER. The author thanks J. J. Berthelier, the PI of this instrument for the use of the data, and Stéphanie Berthelin for the help in data handling. The research leading to these results has also received funding from the European Community's Seventh Framework Programme (FP7/2007-2013) under grant agreement No. 262005.

\section{References}

Akhoondzadeh M, Parrot M and Saradjian M R (2010). Electron and ion density variations before strong earthquakes $(M>6.0)$ using DEMETER and GPS data. Nat Hazards Earth Syst Sci 10: 7-18.

Bankov L G, Parrot M, Heelis R A, Berthelier J-J, Marinov P G and Vassileva A K (2010). DEMETER and DMSP satellite observations of the disturbed $\mathrm{H}^{+} / \mathrm{O}^{+}$ratio caused by Earth's seismic activity in the Sumatra area during December 2004. Adv Space Res 46(4): 419-430.

Berthelier J-J, Godefroy M, Leblanc F, Seran E, Peschard D, Gilbert P and Artru J (2006). IAP, the thermal plasma analyzer on DEMETER. Planet Space Sci 54: 487-501.

Burke W J, de La Beaujardière O, Gentile L C, Hunton D E, Pfaff R F, Roddy P A, Su Y-J and Wilson G R (2009). C/NOFS observations of plasma density and electric field irregularities at post-midnight local times. Geophys Res Lett 36: L00C09, doi:10.1029/2009GL038879.

Freund F (2009). Stress-activated positive hole charge carriers in rocks and the generation of pre-earthquake signals. In: Hayakawa M ed. Electromagnetic Phenomena Associated With Earthquakes. Transworld Research Network, Trivandrum (India), 41-96.

Gokhberg M B, Morgounov V A and Pokhotelov O A (1995). Earthquake Prediction: Seismo-Electromagnetic Phenomena. Gordon and Breach Science Publishers, Reading, Philadelphia, 287pp.

Harrison R G, Aplin K L and Rycroft M J (2010). Atmospheric electricity coupling between earthquake regions and the ionosphere. J Atmos Sol Terrestr Phys 72: 376381.

Hayakawa M (1996). Special issue: Seismo-electromagnetic phenomena. Journal of Atmospheric Electricity 16(3): $247-257$.

Hayakawa M (1997). Electromagnetic Precursors of Earthquakes: Review of Recent Activities. Review of Radio Science, 1993-1996. Oxford University Press, Oxford, 807818.

Hayakawa M ed. (1999). Atmospheric and Ionospheric Electromagnetic Phenomena Associated with Earthquakes. Terra Scientific Publishing Company (TERRAPUB), Tokyo, 997pp.

Hayakawa M ed. (2002). Seismo-electromagnetics. J Atmos Electricity 22(3): 115-222.

Hayakawa M (2009). Electromagnetic Phenomena Associated With Earthquakes. Transworld Research Network, Trivandium (India), 279pp.

Hayakawa M and Fujinawa Y (1994). Electromagnetic Phenomena Related to Earthquake Prediction. TERRAPUB, Tokyo, 677pp.

Hayakawa M and Molchanov O A eds. (2002). Seismo Electromagnetics: Lithosphere-Atmosphere-Ionosphere Coupling. TERRAPUB, Tokyo, 477pp.

Hayakawa M, Molchanov O A, Kodama T, Afonin V V and Akentieva O A (2000). Plasma density variations observed on a satellite possibly related to seismicity. $A d v$ Space Res 26(8): 1 277-1 280.

Hayakawa M, Molchanov O A, Biagi P and Vallianatos F eds. (2004). Seismo electromagnetics and related phenomena. Physics and Chemistry of the Earth 29: 287662.

He Y F, Yang D M, Zhu R, Qian J D and Parrot M (2010). Variations of electron density and temperature in iono- 
sphere based on the DEMETER ISL data. Earthquake Science 23(4): 349-355, doi:10.1007/s11589-010-0732-8.

Kelley M C (2009). The Earth's Ionosphere: Plasma Physics and Electrodynamics. Academic Press, San Diego, 556pp.

Lebreton J P, Stverak S, Travnicek P, Maksimovic M, Klinge D, Merikallio S, Lagoutte D, Poirier B, Kozacek Z and Salaquarda M (2006). The ISL Langmuir probe experiment and its data processing onboard DEMETER: Scientific objectives, description and first results. Planet Space Sci 54: 472-486.

Liu J Y, Chen Y I, Chuo Y J and Chen C S (2006). A statistical investigation of pre-earthquake ionospheric anomaly. $J$ Geophys Res 111: A05304, doi:10.1029/2005JA011333.

Molchanov O A (1993). Wave and plasma phenomena inside the ionosphere and magnetosphere associated with earthquakes. In: Ross Stone W ed. Review of Radio Science 1990-1992. Oxford University Press, Oxford, 591-600.

Molchanov O A and Hayakawa M (2008). SeismoElectromagnetics and Related Phenomena: History and Latest Results. TERRAPUB, Tokyo, 189pp.

Nemec F, Santolík O and Parrot M (2009). Decrease of intensity of ELF/VLF waves observed in the upper ionosphere close to earthquakes: A statistical study. J Geophys Res 114: A04303, doi:10.1029/2008JA013972.

Nemec F, Santolík O, Parrot M and Berthelier J-J (2008). Spacecraft observations of electromagnetic perturbations connected with seismic activity. Geophys Res Lett 35: L05109, doi:10.1029/2007GL032517.

Ouyang X Y, Zhang X M, Shen X H, Liu J, Qian J D, Cai J A and Zhao S F (2008). Ionospheric $N_{\mathrm{e}}$ disturbances before 2007 Pu'er, Yunnan, China, earthquake. Acta Seismologica Sinica 21(4): 425-437, doi:10.1007/s11589-0080425-8.

Parrot M ed. (2006). Special Issue: First Results of the DEMETER Micro-satellite. Planet Space Sci 54(5): 411-558.

Parrot M, Berthelier J-J, Lebreton J P, Sauvaud J A, Santolík O and Blecki J (2006). Examples of unusual ionospheric observations made by the DEMETER satellite over seismic regions. Physics and Chemistry of the Earth 31: 486-495, doi:10.1016/j.pce.2006.02.011.

Parrot M and Johnston M (1989). Special Issue: Seismoelectromagnetic Effects. Phys Earth Planet Inter 57(1-2): $1-177$.

Parrot M and Johnston M (1993). Special Issue: Seismoelectromagnetic Effects. Phys Earth Planet Inter 77(1-2): $1-141$.

Píša D, Parrot M and Santolík O (2011). Ionospheric density variations recorded before the $2010 M_{\mathrm{W}} 8.8$ earthquake in Chile. J Geophys Res 116: A08309, doi:10.1029/2011JA016611.

Pulinets S A (2007). Natural radioactivity, earthquakes, and the ionosphere. Eos Trans $A G U$ 88(20): 217.

Pulinets S A (2009). Physical mechanism of the vertical elec- tric field generation over active tectonic faults. Adv Space Res 44(6): 767-773, doi:10.1016/j.asr.2009.04.038.

Pulinets S A and Boyarchuk K A (2004). Ionospheric Precursors of Earthquakes. Springer, Hedelberg, New York, 316 pp.

Sarkar S, Gwal A K and Parrot M (2007). Ionospheric variations observed by the DEMETER satellite in the midlatitude region during strong earthquakes. J Atmos Sol Terr Phys 69: 1 524-1 540.

Su S Y, Liu C H, Ho H H and Chao C K (2006). Distribution characteristics of topside ionospheric density irregularities: Equatorial versus midlatitude regions. J Geophys Res 111: A06305, doi:10.1029/2005JA011330.

Su Y Z, Bailey G J and Oyama K I (1998). Annual and seasonal variations in the low-latitude topside ionosphere. Ann Geophys 16(8): 974-985.

Tronin A A (2006). Remote sensing and earthquakes: A review. Physics and Chemistry of the Earth 31: 138-142.

Zeng Z C, Zhang B, Fang G Y, Wang D F and Yin H $\mathrm{J}$ (2009). The analysis of ionospheric variations before Wenchuan earthquake with DEMETER data. Chinese $J$ Geophys 52(1): 11-19.

Zhang X, Shen X, Liu J, Ouyang X, Qian J, and Zhao S (2009c). Analysis of ionospheric plasma perturbations before Wenchuan earthquake. Nat Hazards Earth Syst Sci 9: 1 259-1 266.

Zhang X, Zeren Z, Parrot M, Battiston R, Qian J and Shen X (2011). ULF/ELF ionospheric electric field and plasma perturbations related to Chile earthquakes Adv Space Res 47(6): 991-1 000, doi:10.1016/j.asr.2010.11.001.

Zhang X M, Liu J, Shen X H, Parrot M, Qian J D, Ouyang X Y, Zhao S F and Huang J P (2010b). Ionospheric perturbations associated with the M8.6 Sumatra earthquake on 28 March 2005. Chinese J Geophys 53(3): 567-575.

Zhang X M, Qian J D, Ouyang X Y, Shen X H, Cai J A and Zhao S F (2009a). Ionospheric electromagnetic perturbations observed on DEMETER satellite before Chile M7.9 earthquake. Earthquake Science 22: 251-255.

Zhang X M, Qian J D, Ouyang X Y, Cai J A, Liu J, Shen X H and Zhao S F (2009b). Ionospheric electro-magnetic disturbances prior to Yutian 7.2 earthquake in Xinjiang. Chin J Space Sci 29(2): 213-221 (in Chinese with English abstract).

Zhang X M, Shen X H, Liu J, Ouyang X Y, Qian J D and Zhao S F (2010a). Ionospheric perturbations of electron density before the Wenchuan earthquake. International Journal of Remote Sensing 31(13): 3 559-3 569.

Zhu R, Yang D M, Jing F, Yang J Y and Ouyang X Y (2008). Ionospheric perturbations before Pu'er earthquake observed on DEMETER. Acta Seismologica Sinica 21(1): 77-81, doi:10.1007/s11589-008-0077-8.

Zlotnicki J, Li F and Parrot M (2010). Signals recorded by DEMETER satellite over active volcanoes during the period 2004 August-2007 December. Geophys J Inter 183(3): $1332-1347$. 